Teknokultura. Revista de Cultura Digital y Movimientos Sociales

ISSNe: 1549-2230

\title{
Reseña/Review (Prada, Albino, "Crítica del hipercapitalismo digital”, Madrid, Catarata, ISBN: 978-84-9097-657-9, 141 págs., 2019).
}

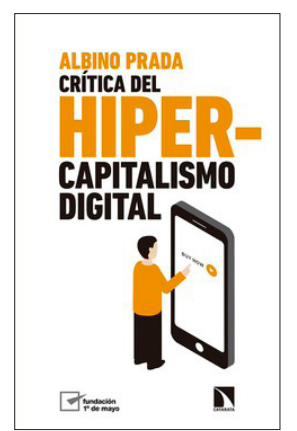

El capitalismo cambia, se expande, evoluciona. $\mathrm{Y}$ en su avance explora nuevos horizontes, ensaya nuevos límites y moviliza formas cada vez más sofisticadas para su supervivencia. Esta singular capacidad de mutación exhibe una 'nueva piel' (Arias y Costas, 2016) en el ecosistema digital, donde la participación de fondos de inversión globales en las más variadas empresas (financieras, industriales, de servicios) crea un desequilibrio de fuerzas y abre un escenario del que se ocupa el economista Albino Prada (2019) en su último ensayo Crítica del hipercapitalismo digital. En un contexto donde la digitalización progresa aceleradamente, y con ella el cambio de modelo - tecnológico y económico -, el autor rastrea los nuevos productos, procesos y modelos de negocio que resultan de tales disrupciones, con una mirada atenta a los agentes que la encabezan y a la (des)regulación que la hace posible. Desde una aproximación crítica, este texto supone un esfuerzo doble no solo por caracterizar el 'hipercapitalismo' digital e insistir en los efectos desintegradores de esta economía 4.0 - en ámbitos como el empleo y la política -, sino por plantear además un programa de medidas que ponga coto a sus excesos y a su modelo incontestable.

En el prólogo, Bruno Estrada sintetiza el concepto de 'hipercapitalismo' como la capacidad desarrollada por las élites extractivas para obtener una doble apropiación (p. 7), una tradicional y otra innovadora, resultado de la intensiva digitalización acometida durante los últimos años. En esta línea, Prada constata en la primera parte del libro el control que empresas líderes en distribución, publicidad o servicios como Facebook, Amazon o Alphabet Google han llegado a acumular en nuestros días. Controladas por grupos de inversión global y en sintonía con grandes firmas tecnológicas como Microsoft o Apple, estos entramados están diseñando un mundo a su medida, acaparando cada vez más poder y autoridad en forma de reducidos oligopolios que monetizan un creciente número de necesidades sociales. En este contexto, la digitalización de las actividades productivas, financieras, comerciales y de ocio ha situado los flujos masivos de datos e información en el centro de la economía, confiriendo gran poder sobre el mercado a las corporaciones que gestionan esta tecnología 4.0. En este marco, donde todos los aspectos de la vida social se subordinan a la lógica de mercado, esta economía de mercado amenaza con mutar en una sociedad global de mercado. Esta mercantilización es posible gracias al reciente desarrollo de las tecnologías de la información y la comunicación (TIC) que permiten la comunicación masiva a coste muy reducido y el acceso gratuito a una gran variedad de servicios.

No obstante, pese a su potencial democratizador, Prada cuestiona las posiciones 'tecnoptimistas' que solo ven en la tecnología la solución a problemas de nuestros días - como la pobreza o el cambio climático - sin interrogar sus limitaciones y los posibles efectos perversos que derivan de esta digitalización y monetización de todos los dominios de nuestra vida. En el empleo, por ejemplo, la introducción de la tecnología más avanzada ha provocado una oleada automatizadora en los más variados procesos productivos. El impacto de esta digitalización sobre el empleo y los desafíos de la cuarta revolución industrial ya estuvieron en el centro del Foro de Davos de 2016, hasta donde Prada retrocede para abordar la acuñada como 'amenaza de los robots'. Su efecto, concluye, es notable: a más digitalización, más riqueza, con menos empleo y de peor calidad. Así, la destrucción de empleo a corto plazo, promovida por la automatización de aquellas tareas más rutinarias, erosiona la financiación de los sistemas de protección social y acrecienta las desigualdades existentes. Una merma que estas megacorporaciones globales no contribuyen a salvar, con el agravante de que gran parte de su desarrollo tecnológico procede en buena medida de investigaciones financiadas con esfuerzo público. Así es como en el contexto de esta economía 4.0, donde cada vez se precisa de menos trabajo humano, asistimos al debilitamiento de relaciones laborales estables. En su lugar proliferan jornadas laborales difusas, parciales e inestables en las que el/la trabajador/a ha de estar siempre disponible ante una eventual demanda (Moruno, 2018).

Más allá del empleo, el impacto del 'hipercapitalismo' se deja sentir también sobre la política. A partir del caso de Estados Unidos, cuna de estos grandes oligopolios globales, Prada expone cómo este hipercapitalismo proyecta un Estado débil frente al poder global de estas megacompañías, resultado de la deslocalización geográfica del empleo y de la tributación de estos operadores en otros países (Prada, 2019, p. 41). Así sucede en el caso de las 'GAFAM', cuyos beneficios multimillonarios no retornan al Estado en forma de impuestos, dada

Este acrónimo se utiliza para designar al conjunto de las cinco grandes empresas Google, Apple, Facebook, Amazon y Microsoft. 
la exigua plantilla de trabajadores en el propio país y su evasión a través de paraísos fiscales. Esta capacidad de influencia, alerta el economista, podría impulsar un régimen postdemocrático donde la toma de decisiones correría a cargo de estas nuevas élites empresariales. A lo largo de estas páginas Prada se sitúa en la era de la alta tecnología (Prada, 2019, p. 51) y se interroga sobre si es preciso imponer límites al cambio tecnológico. Así, frente a la creencia 'tecnopolita' de que la tecnología por sí misma resolverá nuestros problemas y redundará en un mayor bienestar social, el autor plantea un análisis más ponderado de este desarrollismo tecnológico con base en una evaluación de sus riesgos. A propósito de la inteligencia artificial (IA) y la selección genética, apela cabalmente al principio de precaución como criterio rector para evitar incurrir en un 'solucionismo tecnológico' ciego (Morozov, 2015).

La primera parte se completa con un análisis donde el autor pone el foco sobre la doble abducción acometida por la racionalidad neoliberal que somete no solo a los sujetos sino también al Estado a una internalización de la lógica de mercado y de la competencia, moldeando así su desempeño. Este despliegue total de la razón neoliberal se canaliza a través de un discurso de hierro en palabras de terciopelo (Prada, 2019, pp. 61 y 66) por el que los individuos, por una parte, sucumben al paradigma productivo de la empresa como modelo de subjetivación. Convertidos en sujetos neoliberales, éstos se ven impelidos a una rivalidad y optimización incesante de sí mismos en un marco donde las ideas de éxito y elección permanente atraviesan todas las esferas de sus vidas. De igual modo, el Estado se pliega ante esta razón neoliberal y actúa no solo como un garante del mercado, sino que acaba sometido a su propia lógica competitiva. Esta conversión del Estado social en neoliberal limita su papel a asegurar no ya una distribución justa de la riqueza, sino aquella determinada por el mercado y comandada por una élite. Esta doble abducción - del ciudadano y del Estado - debe ser contestada, justifica Prada, mediante una razón alternativa que promueva relaciones de cooperación y puesta en común y donde la idea de compartir desplace a la de competir.

La segunda parte del libro explora los efectos derivados de este 'hipercapitalismo' y desglosa algunas de las reformas - ya anticipadas en la primera parte - para frenar su alcance. El autor centra su análisis en el impacto sobre el empleo, las actividades y la economía. Señala cómo el reciente desarrollo de las TIC ha favorecido la progresiva digitalización de un número cada vez mayor de actividades y la concentración de esta tecnología 4.0 en manos de oligopolios mundiales, conformando así un sector industrial a su medida y generando una mayor desigualdad social. En lo que respecta al empleo, esta nueva economía se muestra capaz de producir más riqueza con menos empleo humano directo, de manera que la digitalización se revela como un factor destructor de empleo. Una destrucción que ni siquiera el impulso del sector de las telecomunicaciones, con el consiguiente aumento en la contratación, consigue compensar. Para poner coto a los efectos de esta economía 4.0 y frenar el avance de una sociedad global de mercado, Prada pro- pone una doble redistribución tanto del trabajo humano necesario como de la riqueza generada cada vez con menos trabajadores.

Asimismo advierte de las transformaciones que esta digitalización introduce en la naturaleza de algunas actividades, promoviendo una mayor dependencia, superficialidad y complacencia entre sus usuarios. Una automatización que al adormilar los talentos más especializados en pro de los más rutinarios estrecharía nuestra propia capacidad analítica y entrañaría riesgos como la monopolización del mercado por parte de estas grandes empresas, equívocos derivados de predicciones algorítmicas erróneas o la acumulación indebida de datos personales. Finalmente, Prada analiza la erosión del estado de bienestar, fruto de la revolución tecnológica 4.0. Parafraseando a Krugman, sostiene que los propietarios del capital (robots, algoritmos, capital científico, etc.) se apoderan de los beneficios generados a partir de la automatización y la digitalización. Estos procesos llevan consigo una disminución del empleo social necesario, lo que reduce los recursos del sistema público de protección social. En una lectura contemporánea de Marx, el economista expone la apropiación que la industria privada realiza de aquellos desarrollos y conocimientos científico-técnicos conseguidos a través de la inversión pública. Esta abducción de lo social por lo empresarial se traduce en que la riqueza nacional depende cada vez en menor medida del trabajo vivo y queda supeditada en cambio al desarrollo científico y tecnológico (Prada, 2019, p. 103).

Con la mirada puesta en el contexto español y europeo, Prada cierra este volumen con un extenso capítulo dedicado a contener el avance del 'hipercapitalismo' digital a partir de un conjunto de medidas. Agrupadas en cinco bloques, este catálogo de propuestas evidencia el compromiso del autor con el tránsito hacia una sociedad 5.0, a imagen de Japón, donde la digitalización esté al servicio de un desarrollo inclusivo y sostenible. Para ello, propone en primer lugar reajustar lo local y lo global, priorizando el abastecimiento y el empleo de proximidad y limitando en lo posible el dominio de estos grandes monopolios tecnológicos (Prada, 2019, p. 108). Esta apuesta se basa en un modelo de crecimiento que no quede supeditado a la exportación de bienes y desempleo y que, de ser posible, vincule la gestión de las TIC a una reflexión sobre la soberanía tecnológica. Su proyecto pasa, además, por iniciar una fiscalidad internacional (Prada, 2019, p. 112) que impida la optimización y/o la evasión fiscal en centros offshore de estas megacorporaciones por la vía de la deslocalización y les permita crear un régimen fiscal a su medida. En esta misma línea, sugiere reforzar la fiscalidad nacional a partir de la aplicación del principio de progresividad, de modo que el aporte de las rentas más bajas deje de ser proporcionalmente superior al de las más altas (Prada, 2019, p. 117). A su vez aconseja dejar de penalizar fiscalmente a sectores intensivos en empleo - sanidad y educación - frente a aquellos altamente robotizados y que más lo sustituyen, como la industria energética y financiera. 
Por otra parte, la viabilidad del sistema fiscal, muy dependiente de las rentas salariales, se ve comprometida por la deslocalización de la actividad y la disminución del empleo humano necesario (y remunerado). Ante este problema, su propuesta pasa por redistribuir ocupaciones y rentas a través de la implementación de una renta básica universal (Prada, 2019, p. 123). Este ingreso, según el autor, permitiría redistribuir tanto el trabajo humano necesario como la riqueza generada con esta disminución de trabajo humano directo, además de reconocer y remunerar tareas esenciales para la sociedad como los cuidados. Por último, Prada recomienda equilibrar mercado, Estado y pro-común y aboga por el blindaje de aspectos de la vida social, excluyéndolos tanto del mercado como del Estado, así como por la potenciación de un pro-común colaborativo basado en el trabajo emancipado, en contraste con los 'infomonopolios' y el 'hipercapitalismo' cognitivo (Prada, 2019, p. 128).
Esta combinación de elementos descriptivos y propositivos convierten a Crítica del hipercapitalismo digital en un título esencial para comprender los fundamentos de este modelo y sus efectos. Estamos ante un retrato riguroso del actual escenario económico y tecnológico y de su impacto sobre las diversas áreas de la sociedad. Una descripción meticulosa en la que, sin caer en la 'tecnofobia', Prada cuestiona dicho modelo y ofrece una salida a la hiperconcentración y al aumento de la desigualdad. Es ahí, precisamente en su vocación propositiva, donde radica la potencia de este libro. Un texto que señala el camino para superarlo, argumentando que existen alternativas con las que resistir a una sociedad global de mercado y dar la bienvenida a una sociedad más justa. Un nuevo equilibrio que abra paso una economía de mercado basada en la competencia real, un sector público fuerte que no se vea coartado por la lógica privada y donde el pro-común vaya ganando cada vez más espacio.

\section{Referencias}

Arias, X. C., y Costas, A. (2016). La nueva piel del capitalismo. Barcelona: Galaxia Gutenberg. Morozov, E. (2015). La locura del solucionismo tecnológico. Madrid: Katz Editores y Clave Intelectual. Moruno, J. (2018). No tengo tiempo. Geografias de la precariedad. Madrid: Akal. https://orcid.org/0000-0002-7895-9567 